\title{
OCORRÊNCIA DE AFLATOXINAS EM MILHO DESTINADO À ALIMENTAÇÃO DE AVES NO ESTADO DA BAHIA
}

\section{A.V.A.F. Almeida1 ${ }^{\text {, M.B. Botura }}{ }^{1}$, R.D. Abreu ${ }^{2}$, T.C.C. Bittencourt ${ }^{3}$, M.J.M. Batatinha ${ }^{1}$}

${ }^{1}$ Universidade Federal da Bahia, Escola de Medicina Veterinária, Departamento de Patologia e Clínicas, Laboratório de Toxicologia, R. Adhemar de Barros, 500, CEP 40170-110, Salvador, BA, Brasil. E-mail: anavafs@gmail.com

\section{RESUMO}

\begin{abstract}
O objetivo deste estudo foi determinar a ocorrência de aflatoxinas (AFs) em milho destinado à alimentação de aves no Estado da Bahia. Oitenta amostras de milho foram coletadas de duas fábricas produtoras de ração durante o período de fevereiro de 2005 a janeiro de 2006. As análises de AFs foram realizadas por meio da técnica de fluorimetria com colunas de imunoafinidade (Aflatest $\left.{ }^{\circ}, \mathrm{Vicam}\right)$. Os resultados revelaram que oito $(10 \%)$ amostras estavam contaminadas, com níveis variáveis de 1 a $5 \mu \mathrm{g} / \mathrm{kg}$. Estes resultados demonstram a boa qualidade do produto quanto à contaminação por aflatoxinas.
\end{abstract}

PALAVRAS-CHAVE: Aflatoxinas, ocorrência, milho, avicultura.

\section{ABSTRACT}

OCCURRENCE OF AFLATOXINS IN CORN USED AS POULTRY FEED IN THE STATE OF BAHIA, BRAZIL. The objective of this study was to determine the occurrence of aflatoxins in the corn used as poultry feed in the state of Bahia, Brazil. Eighty samples of corn were collected from two poultry feed factories between February 2005 and January 2006. The aflatoxins analyses were performed using a fluorometric technique with commercial immunoaffinity columns (Aflatest ${ }^{\circledR}$, Vicam). The results revealed contamination in $8(10 \%)$ of the samples, with levels varying from 1 to $5 \mu \mathrm{g} / \mathrm{kg}$. These results reflect the good quality of this product in regard to contamination by aflatoxins.

KEY WORDS: Aflatoxins, occurrence, corn, poultry.

\section{INTRODUÇÃO}

Atualmente, o Brasil ocupa a posição de maior exportador e terceiro maior produtor mundial de carne de frango, encontrando-se o plantel avícola nacional sob privilegiada condição de controle sanitário (Associação Brasileirados Produtorese EXPORTADORES DE FRANGO, 2007).

A avicultura no Estado da Bahia destaca-se como um dos setores agropecuários em grande expansão, ocupando posição deliderança na produção de carne de frango das regiões Norte e Nordeste do país. Este quadro tem sido favorecido, dentre outros, pela crescente produção de grãos no Estado, especialmente de milho (COMPANHIA NACIONAL DE ABASTECIMENTO, 2007).

Uma variedade de fatores pode interferir negativamente na produção deste cereal, destacando-se a contaminação por toxinas fúngicas, especialmenteas aflatoxinas (SMITH; Moss, 1985), tornando necessária a implantação e manutenção de medidas preventivas para garantia da sua qualidade.

As aflatoxinas têm sido referidas como potentes agentes carcinogênicos, mutagênicos e teratogênicos (International Agency for Research on Cancer, 1993; CHANet al.,2003; WANGIKARetal., 2005), podendocausar severos danos à saúde pública e animal (Hussein; BRASEL, 2001). Em aves, essas toxinas são responsáveis por altas taxas de mortalidade, além de promoverem diversos efeitos tóxicos, incluindo alterações no sistema imunológico (EBRAHIMI; SHAHSAVANDI, 2008), redução da conversão alimentar (SANTIN et al.,2003) e decréscimo na produção de ovos (ExARCHOS; GENTRY, 1982).

A contaminação de produtos agrícolas por fungos toxígenos e a consequente produção de micotoxinas

\footnotetext{
${ }^{2}$ Universidade Federal do Recôncavo da Bahia, Departamento de Zootecnia, Cruz das Almas. BA, Brasil. ${ }^{3}$ Universidade Federal da Bahia, Escola de Medicina Veterinária, Departamento de Produção Animal, Salvador, BA, Brasil.
} 
estão vinculadas a diversos fatores, incluindo as condições inadequadas de plantio, colheita, transporte e armazenamento Diniz, 2002; BogantesLEDEZMA et al., 2004), associadas às variáveis climáticas favoráveis (PonTES NetTo et al., 2002), umidade, atividade de água (DoHLMAN, 2003) e composição do substrato, especialmente o conteúdo de lipídios e carboidratos (Yu et al., 2003).

As microrregiões onde estão localizadas as fábricas utilizadas neste estudo apresentam clima sub-úmido a úmido,com temperaturasmédiaseíndicepluviométrico que são elevados (BAHIA, 2003), propícios ao desenvolvimento de fungos toxigênicos (YANAKA et al., 2009).

A maioria das pesquisas sobre micotoxinas em alimentos no Brasil tem sido realizada nas regiões Sul eSudeste, o que dificulta a obtenção de um panorama representativo do país (SABINO; RoDRIGUEZ-AMAYA,1993). NoEstado da Bahia, as publicações científicas referentes à contaminação de produtos alimentícios por micotoxinas restringem-se à ocorrência de aflatoxinas em milho armazenado (BAUTISTA et al., 1989), amendoim e subprodutos (Mirandaet al.,1988; Batatinhaetal., 2003), $\mathrm{AFM}_{1}$ em leite de cabra (Botura et al., 2005), aflatoxinas, ocratoxinas (Simasetal.,2007)efumonisinas (BATATinHa et al., 2007) em bagaço de cevada.

$\mathrm{O}$ crescimento gradativo da indústria avícola no Estado e a importância do milho como principal componente da alimentação de aves, associados às condições climáticas locais e à escassez de informações científicas no Estado sobre a contaminação de produtos alimentícios por micotoxinas, justificaram a realização deste estudo, o qual objetivou determinar a ocorrência de aflatoxinas em milho destinado à alimentação de aves no Estado da Bahia.

\section{MATERIAL E MÉTODOS}

\section{Coleta das amostras}

As amostras de milho utilizadas neste estudo foram provenientes de duas fábricas produtoras de ração destinada à alimentação de aves, localizadas nos Municípios de Conceição da Feira (Fábrica A) e Entre Rios (Fábrica B), Estado da Bahia. A seleção destas fábricas ocorreu em função de sua inserção no quadro de indústrias avícolas de destaque no Estado e da localização adequada à operacionalização das coletas, as quais foram realizadas semanalmente durante o período de fevereiro de 2005 a janeiro de 2006, selecionando-se um total de 80 amostras.

O processo de amostragem realizado foi baseado no sistema adotado pela União Européia (Ec,1998). A quantidade de milho a ser amostrada (amostra coletiva) foi estabelecida com base no conhecimento do volume de produção (em toneladas) de cada fábrica de ração durante um turno de trabalho, utilizando-se a seguinte fórmula: $\sqrt{20 \times n}=x$; onde " $n$ " corresponde ao volume de produção diária em toneladas e " $x$ " à quantidade em quilogramas da amostra coletiva desejada, a qual foi dividida em frações (incrementos) e obtida em intervalos de tempo determinados de acordo com a duração do turno de trabalho, durante a transferência do milho moído para a moega. Após a homogeneização da amostra coletiva, foram retiradas duas amostras finais (de $1 \mathrm{~kg}$ cada) para a realização das análises laboratoriais. Estas amostras foram acondicionadas individualmente em sacos de papel pardo, envoltas em sacos plásticos, rotuladase mantidas sob congelamento à temperatura de $-20^{\circ} \mathrm{C}$ até o momento das análises.

Questionários foram aplicados para obtenção de informações sobre a origem do milho utilizado, condições das instalações e equipamentos das fábricas, duração e condições de armazenamento dos grãos.

\section{Determinação da umidade das amostras}

As análises do teor de umidade das amostras de milho foram realizadas segundo a técnica descrita por SiLVA; QueIroz (2002).

\section{Determinação de aflatoxinas totais}

A análise de aflatoxinas foi realizada empregando-se a técnica de fluorimetria/ colunas de imunoafinidade - Aflatest (VICAM, 2002), descrita a seguir. Cinquenta gramas de cada amostra, previamente triturada, foram homogeneizadas em blender com 100 mLde solução metanol:água destilada (80:20) (Merck, grau HPLC) e5 g de $\mathrm{NaCl}$ (Synth,P.A.) durante 1 minuto. Após filtração, tomou-se uma alíquota de $10 \mathrm{~mL}$ e completou-se o volume para $50 \mathrm{~mL}$ com água destilada. Em seguida, procedeu-se uma segunda filtração em papel de microfibra (Whatman 934AH), retirando-se $10 \mathrm{~mL}$ deste filtrado homogeneizado para aplicação na coluna. A pós a passagem da amostra, a coluna foi lavada duas vezes com $10 \mathrm{~mL}$ deágua destilada e, em seguida, com $1 \mathrm{~mL}$ de metanol para eluir as aflatoxinas ligadas aos anticorpos monoclonais. Posteriormente, $1 \mathrm{~mL}$ do revelador Aflates ${ }^{\circledR}$ foi adicionado ao eluato e realizada a leitura em fluorímetro (Série 4, Vicam). O limite de detecção da metodologia empregada foi de $1 \mu \mathrm{g} / \mathrm{kg}$.

\section{Controle da qualidade analítica}

Testes em triplicata foram utilizados para validar o protocolo de análise de aflatoxinas empregadoneste trabalho. Amostras de milho, nas quais não foram detectadas aflatoxinas, foram contaminadas com 1 ppbdos padrões de cada toxina, totalizando 4 ppb de 
aflatoxinas $\mathrm{B}_{1}, \mathrm{~B}_{2}, \mathrm{G}_{1}$ e $\mathrm{G}_{2}$ (Sigma). Após a extração, o percentual de recuperação foi calculado de acordo com CHAsin et al. (1998). O percentual de recuperação obtido foi de $108,2 \%$ e coeficiente de variação de $24,8 \%$, indicando, respectivamente, exatidão e precisão do método, uma vez que atendem aos critérios adotados pelaEuropean COMMUNities (1998) eHorwitz et al. (1980).

\section{Análise estatística}

As diferenças de contaminação das amostras entre as fábricas foram analisadas por meio do teste do Qui-quadrado, empregando-se o software SPSS(Versão Inc. SPSS Base 11.0 User's guide. Chicago, SPSS Inc. 2001).

\section{RESULTADOS E DISCUSSÃO}

As informações obtidas pelos questionários aplicados nas fábricas evidenciaram que, em ambas, o milho era originado das cidades de Irecê ou Barreiras, Bahia. O controle de qualidade dos grãos recebidos nestas fábricas era realizado por meio de sua classificação (ardidos, quebrados e brotados) e análises do teor de umidade, cujos resultados eram determinantes na recusa ou recebimento da carga desta matériaprima. O limite máximo de umidade adotado pelas empresas foi de $13 \%$. O período médio de armazenamento do cereal foi variável de 8 a 21 e 8 dias, respectivamente, nas fábricas $\mathrm{A}$ e $\mathrm{B}$. A produção diária média de ração na fábrica $A$ era de 50 e na $B$, de 100 toneladas. As condições das instalações físicas e dos equipamentos, em ambas, apresentaram-se em bom estado de conservação e higiene.

Os resultados das análises de aflatoxinas $\left(B_{1}+B_{2}\right.$ $+\mathrm{G}_{1}+\mathrm{G}_{2}$ ) em grãos de milho oriundos destas fábricas revelaram que, do total de 80 amostras avaliadas, oito (10\%) estavam contaminadas com níveis variáveis de 1 a $5 \mu \mathrm{g} / \mathrm{kg}$ (Tabela 1), valores considerados abaixo do nível máximo $(50 \mu \mathrm{g} / \mathrm{kg})$, permitido pela Portaria MA/SNAD/SFAn ${ }^{\circ} .7$ de 1988 para qualquer matériaprima a ser utilizada, diretamente ou como ingrediente, para rações destinadas ao consumo animal (BRASIL, 1988).

No Brasil, a maioria dos trabalhos de ocorrência destas toxinas em milho apresenta percentuais de contaminação variáveis de 2,5a 90,9\% e níveis de 0,15 a $3.000 \mu \mathrm{g} / \mathrm{kg}$ (GONÇALEZet al., 2001;GLóRIA et al.,2004; SEKIYAMA et al., 2005), embora resultados de algumas investigações não tenham demonstrado a presença destas toxinas (PRADO et al., 1995; BITTENCOURT et al., 2005), mesmo quando observado o crescimento de fungos aflatoxigênicos (NiCÁcIo et al., 1995; DiLKIN et al., 2000).
No Estado da Bahia, resultados de um único estudo realizado por BAUTISTA et al. (1989) em amostras de milho armazenado, oriundo do Município de Irecê e destinado à alimentação humana e animal, revelaram percentual de contaminação de $12 \%$ para aflatoxina $\mathrm{B}_{1}$, semelhante àquele encontrado neste trabalho (10\%). No entanto, os níveis da toxina encontrados pelos autores foram consideravelmente elevados $(1.000$ a $1.875 \mu \mathrm{g} / \mathrm{kg})$, com valor médio de contaminação de $1.413 \mu \mathrm{g} / \mathrm{kg}$, aproximadamente 70 vezes o limite máximo de aflatoxinas totais permitido em milho destinado à alimentação humana $(20 \mu \mathrm{g} / \mathrm{kg}) \mathrm{e}$ 28 vezes o valor máximo aceitável para a alimentação animal $(50 \mu \mathrm{g} / \mathrm{kg})$, de acordo com a legislação brasileira (BRASIL, 1988, 2002).

O maior número de amostras positivas foi encontrado na Fábrica B, quando comparado com a Fábrica A (Tabela 1), embora essa diferença não tenha sido estatisticamente significante. Os reduzidos percentuais e níveis de contaminação encontrados nas amostras provenientes de ambas as fábricas podem ter resultado das boas práticas de manejo adotadas, tais como curto período de armazenamento, controle de qualidade do milho durante a recepção dos lotes e monitoramento da temperatura dos silos, o que contribuiu para a manutenção da boa qualidade dos grãos. No entanto, a ausência de monitoramento para a presença dessas toxinas no milho imediatamente aportado nas referidas fábricas não nos permite afirmar que as amostras positivas encontradas neste estudo, embora em baixos níveis, tenham sido contaminadas durante o período de estocagem do milho nelas, ou anteriormente à sua chegada nas respectivas fábricas.

Resultados de análise deaflatoxinas em ração para frangos decorteem granjas doEstado deGoiás também revelaram baixo percentual de contaminação, 1,66\% (1/60), com nível de $28 \mu \mathrm{g} / \mathrm{kg}$, eforam associadosà boa qualidade do milho utilizado na fabricação de alimentos para aves (Oliveira et al., 1997).

Tabela 1 - Número de amostras positivas e variações dos níveis de aflatoxinas totais em milho proveniente de fábricas de ração para aves no Estado da Bahia durante o período de fevereiro/2005 a janeiro/2006.

\begin{tabular}{cccc}
\hline Fábricas & $\begin{array}{c}\text { № de } \\
\text { amostras }\end{array}$ & $\begin{array}{c}\text { Total de amostras } \\
\text { positivas* } \%)\end{array}$ & $\begin{array}{c}\text { Variação dos } \\
\text { níveis de } \\
\text { aflatoxinas } \\
(\mu \mathrm{g} / \mathrm{kg})\end{array}$ \\
\hline A & 40 & $2(2,5)$ & $1-4$ \\
B & 40 & $6(7,5)$ & $1-5$ \\
Total & 80 & $8(10,0)$ & $1-5$ \\
\hline
\end{tabular}

*Limite de detecção e quantificação: $1 \mu \mathrm{g} / \mathrm{kg}$ 
O teor de umidade das amostras analisadas neste estudo variou de 10,1 a $13,8 \%$, níveis inferiores ao valor máximo (14,5\%) permitido pelo Ministério da Agricultura e do Abastecimento, conforme Portaria do ${ }^{\circ} .845$ de 1976 (BrasiL, 1976).

Estes reduzidos teores de umidade, encontrados nas amostras de milho avaliadas, podem ter contribuído para os seus baixos níveis e frequência de contaminação. Em amostras de milho armazenado, a ausência de contaminação por aflatoxinas também tem sido atribuída a níveis reduzidos de umidade, entre 13 e 13,5\%, (Prado et al., 1995). Há possibilidade de desenvolvimento de fungos em milho com teor de umidade de $14 \%$ após períodos de armazenamento de até 62 dias (Krabbe et al., 1994). Neste estudo, o período máximo de armazenagem do milho correspondeu a 21 dias na Fábrica A, e nenhuma das amostras analisadas, em ambas as fábricas, apresentou teor de umidade igual ou superior a $14 \%$ após o armazenamento.

Considerando-se a importância econômica e nutricional do milho na indústria avícola e a escassez de informações científicas sobre a sua contaminação por micotoxinas no Estado da Bahia, este estudo contribui para a ampliação do conhecimento sobre o perfil de qualidade desta matéria-prima, constituindo-se no primeiro estudo sobre a ocorrência de aflatoxinas em milho destinado à alimentação de aves no Estado.

Os resultados encontrados sugerem que a baixa frequência e níveis de contaminação por aflatoxinas nas amostras de milho avaliadas podem ser consequência das adequadas práticas de manejo adotadas nessas fábricas, especialmente no que se refere ao controle de qualidade dos grãos recebidos, incluindo a determinação do teor de umidade, o curto período de armazenamento e o satisfatório padrão de higiene das instalações e equipamentos. Além disso, podem ser resultantes das boas práticas agrícolas seguidas durante o desenvolvimento da cultura e póscolheita. No entanto, a detecção dessas micotoxinas nas amostras analisadas, embora em baixos níveis, pode também atuar como indicativo da necessidade de monitoramento programado. Desta forma, contribuindo para a redução dos prejuízos econômicos ao agronegócio e reduzindo os riscos à saúde pública, associados à transmissão dessas toxinas em carne e ovos de aves alimentadas com produtos contaminados (Fraga etal., 1996; Salle etal., 2002; Bahrami, 2004).

\section{AGRADECIMENTOS}

À Fundação de Amparo à Pesquisa do Estado da Bahia (FAPESB) e à Pró-Reitoria de Pesquisa e PósGraduação (PRPPG) da Universidade Federal da Bahia (UFBA) pela concessão de auxílio financeiro.

\section{REFERENCIAS}

ASSOCIAÇÃO BRASILEIRA DOS PRODUTORES E EXPORTADORES DE FRANGOS. Relatório Anual 2006. Disponível em: <http://www.abef.com.br/ Relatorios_Anuais. asp>. Acesso em: 18 ago. 2007.

BAHIA. Superintendência de Estudos Econômicos e Sociais da Bahia. Uso atual das terras: Bacias do Recôncavo Norte e do Rio Inhambupe. Série Estudos e Pesquisas, n.64, p.114, 2003.

BAHRAMI, A.M. Distribution of aflatoxin $B_{1}$ from poultry feed to different tissue of broilers in tropical weather. In: INTERNATIONAL CONFERENCE OF THE ASSOCIATION OF INSTITUTIONS FOR TROPICAL VETERINARY MEDICINE, 11; VETERINARY ASSOCIATION MALAYSIA CONGRESS, 16., 2004, Petaling, Jaya. Proceedings. Petaling: 2004. p.244-246.

BATATINHA, M.J.M.; SANTOS, M.M.; BOTURA, M.B.; ALMEIDA, G.N.; DOMINGUES, L.F.; KOWALSKI, C.H.; MALLMANN, C.A. Ocorrência de aflatoxinas em amendoim e seus produtos comercializados no Estado da Bahia durante o ano de 2002. Revista do Instituto Adolfo Lutz, v.62, n.3, p.183-187, 2003.

BATATINHA, M.J.M.; SIMAS, M.M.S.; BOTURA, M.B.; BITENCOURT, T.C.; REIS, T.A.; CORREA, B.

Fumonisins in brewers grain (barley) used as dairy cattle feed in the State of Bahia, Brazil. Food Control, n.18, p.608-612, 2007.

BAUTISTA, A.R.P.L.; OLIVEIRA, M.Z.A.; MIRANDA, M.S.; SALES, L.A. Aflatoxinas em grãos de milho armazenado no Estado da Bahia. Revista da Sociedade Brasileira de Toxicologia, v.2, n.1, p.24-25, 1989.

BITTENCOURT, A.B.F.; OLIVEIRA, C.A.D.; DILKIN, P.; CORREA, B. Mycotoxin occurrence in corn meal and flour traded in São Paulo, Brazil. Food Control, v.16, n.2, p.117-120, 2005.

BOGANTES-LEDEZMA, P.; BOGANTES-LEDEZMA, D.; BOGANTES-LEDEZMA, S. Aflatoxinas. Acta Médica Costarricense, v.46, n.4, p.174-178, 2004.

BOTURA, M.B.; SIMAS, M.M.S.; SABINO, M.; BATATINHA, M.J.M. Otimização de metodologia por CCD para determinação de aflatoxina $M_{1}$ em leite de cabra e investigação de sua ocorrência no Estado da Bahia. Revista do Instituto Adolfo Lutz, v.64, n.2, p.193199, 2005.

BRASIL. Ministério da Agricultura. Portaria n ${ }^{\circ} .845$ de 8 de novembro de 1976. Aprova as especificações para a padronização, classificação e comercialização interna do milho. Diário Oficial da União, 19/11/1976. 
BRASIL. Ministério da Agricultura. Portaria nº 07 , de 09 de novembro de 1988. Estabelece os padrões mínimos das diversas matérias primas empregadas na alimentação animal. Diário Oficial da União, 09 de novembro de 1988.

BRASIL. Agência Nacional de Vigilância Sanitária. Resolução - RDC nº. 274, de 15 de outubro de 2002. Aprova o Regulamento Técnico Sobre Limites Máximos de Aflatoxinas Admissíveis no Leite, no Amendoim, no Milho. Diário Oficial da União, 16/10/2002.

CHAN, K.-T.; HSIENTANG HSIEH, D.P.; LUNG, M.L. In vitro aflatoxin $\mathrm{B}_{1}$-induced $\mathrm{p} 53$ mutations. Cancer Letters, v.199, n.1, p.1-7, 2003.

CHASIN, A.A.D.M.; NASCIMENTO, E.D.S.; RIBEIRONETO, L.M.; SIQUEIRA, M.E.P.B.D.; ANDRAUS, M.H.; SALVADORI, M.C.; FERNÍCOLA, N.A.G.D.; GORNI, R.; SALCEDO, S. Validação de métodos em análises toxicológicas: uma abordagem geral. Revista Brasileira de Toxicologia, v.11, n.1, p.1-6, 1998.

COMPANHIA NACIONAL DE ABASTECIMENTO. Indicadores da agropecuária. Disponível em: <http:/ / www.conab.gov.br/conabweb/download/indicadores/IA_ABR_2007.PDF>. Acesso em: 28 jun. 2007.

DILKIN, P.; MALLMANN, C.A.; SANTURIO, J.M.; HICKMANN, J.L. Classificação macroscópica, identificação da microbiota fúngica e produção de aflatoxinas em híbridos de milho. Ciência Rural, v.30, n.1, p.137-141, 2000.

DINIZ, S.P.S.D.S. Micotoxinas. Campinas: Livraria e Editora Rural, 2002. 181p.

DOHLMAN, E. Mycotoxin hazards and regulations: impacts on food and animal feed crop trade. 2003. Disponível em: <http://www.ers.usda.gov/publications/aer828/aer 828h.pdf>. Acesso em: 25 jun. 2007.

EBRAHIMI, M.M.; SHAHSAVANDI, S. Evaluation of antibody levels during simultaneous aflatoxicosis and vaccination against infectious laryngotracheitis in pullets. Biologicals, v.36, p.327-329, 2008.

EUROPEAN COMMUNITIES. Commission Directive 98/53/EC. Laying down the sampling methods and the methods of analysis for the official control of the levels for certain contaminants in foodstuffs. Official Journal of the European Communities, 17/07/1998, n.L201, p.93-101, 1998.

EXARCHOS, C.C.; GENTRY, R.F. Effect of aflatoxin B1 on egg production. Avian Diseases, v.26, n.1, p.191-195, 1982.

FRAGA, M.E.; DIREITO, G.M.; SANTANA, D.M.N.D.; BARROS, G.C.D.; ROSA, C.A.D.R. Determinação por cromatografia em camada delgada de aflatoxinas (B1 e M1) e aflatoxicol em ovos destinados ao comércio. Revista Brasileira de Medicina Veterinária, v.18, n.4, p.172-175, 1996.
GLÓRIA, E.M.D.; CIACCO, C.F.; LOPES FILHO, J.F.; ERICSSON, C.; ZOCCHI, S.S. Distribution of aflatoxin contamination in maize samples. Ciência e Tecnologia de Alimentos, v.24, n.1, p.79-83, 2004.

GONÇALEZ, E.; PINTO, M.M.; FELÍCIO, J.D. Análise de micotoxinas no Instituto Biológico de 1989 a 1999. O Biológico, São Paulo, v.63, n.1/2, p.15-19, 2001.

HORWITZ, W.; KAMPS, L.R.; BOYER, K.W. Quality assurance in the analysis of foods for trace constituents. Journal of the Association of Official Analytical Chemists, v.63, n.6, 1980.

HUSSEIN, H.S.; BRASEL, J.M. Toxicity, metabolism, and impact of mycotoxins on humans and animals. Toxicology, v.167, n.2, p.101-134, 2001.

INTERNATIONAL AGENCY FOR RESEARCH ON CANCER. Some naturally occurring substances: food items and constituents, heterocyclic aromatic amines and mycotoxins. Lyin: IARC, 1993. v.56.

KRABBE, E.L.; JUNIOR, A.M.P.; LAZZARI, F.A.; REGINATTO, M.F. Efeito da umidade e do ácido propriônico sobre as características bromatológicas e microbiológicas de grãos de milho. In: CONFERÊNCIA APINCO, 1994, Campinas. Anais. Campinas: 1994. p.27-28.

MIRANDA, M.S.; CARVALHO, R.; CORRAL, F.; OLIVEIRA, M.Z.; BAUTISTA, A.R.P.L. Pesquisa de aflatoxinas em amendoim comercializado em Salvador, Bahia. In: ENCONTRO NACIONAL DE MICOTOXINAS, 5., 1988, São Paulo. Anais. São Paulo: 1988. p.22.

NICÁCIO, M.A.S.; PRADO, G.; LINARDI, V.R. Determinação de aflatoxina e identificação da microbiota fúngica em milho (Zea mayz) pós-colheita. Arquivos do Instituto Biológico, São Paulo, v.38, n.3, p.851-857, 1995.

OLIVEIRA, M.A.B.; MESQUITA, A.J.; SABINO, M.; CAFÉ, M.B. Ocorrência de aflatoxinas $B_{1}$ e $G_{1}$ em rações para frangos de corte em granjas do Estado de Goiás. Arquivo Brasileiro de Medicina Veterinária e Zootecnia, v.49, n.6, p.701-708, 1997.

PONTES NETTO, D.; ZANLUCHI, A.T.; SASSAHARA, M.; YANAKA, E.K. Micotoxinas em alimentação animal no período de maio/1997 a março/2001 no Laboratório de Toxicologia Veterinária da Universidade Estadual de Londrina - Londrina - PR. SEMINA: Ciências Agrárias, v. 23, n.1, p.63-69, 2002.

PRADO, G.; VIEIRA, M.B.C.M.; SANTOS, J.P.; OLIVEIRA, M.S.D. Ocorrência de micotoxinas em milho pós-colheita e armazenado do Estado de Minas Gerais, safra 1991. Higiene Alimentar, v.9, n.35, p.2427, 1995 
SABINO, M.; RODRIGUEZ-AMAYA, D.B. Mycotoxin research in Brazil. Ciência e Cultura, São Paulo, v.45, n.6, p.359-371, 1993.

SALLE, C.T.P.; RODRIGUES, O.; BAVARESCO, Á.; LORENZINI, G.; MORAES, H.L.D.S.; SILVA, A.B.D.; SALLE, F.D.O.; NASCIMENTO, V.P.; FALLAVENA, L.C. Detecção de aflatoxina B1 no organismo de frangos de corte através do emprego de ensaio imunoenzimático utilizando anticorpos monoclonais (ELISA). Acta Scientiae, v.30, n.1, p.27-30, 2002.

SANTIN, E.; PAULILLO, A.C.; KRABBE, E.L.; ALESSI, A.C.; POLVEIRO, W.J.C.; MAIORKA, A. Low level of aflatoxin in broiler at experimental conditions, use of cell wall yeast as adsorbent of aflatoxin. Archives of Veterinary Science, v.8, n.2, p.51-55, 2003.

SEKIYAMA, B.L.; RIBEIRO, A.B.; MACHINSKI, P.A.; MACHINSKI JÚNIOR, M. Aflatoxins, ochratoxin A and zearalenone in maize-based food products. Brazilian Journal of Microbiology, n.36, p.289-294, 2005.

SILVA, D.J.; QUEIROZ, A.C.D. Análise de alimentos : métodos químicos e biológicos. 3.ed. Viçosa: UFV, 2002. 235p.

SIMAS, M.M.S.; BOTURA, M.B.; CORREA, B.; SABINO, M.; MALLMANN, C.A.; BITENCOURT, T.C.;

BATATINHA, M.J.M. Determination of fungal microbiota and mycotoxins in brewers grain used in dairy cattle feeding in the State of Bahia, Brazil. Food Control, n.18, p.404-408, 2007.
SMITH, J.E.; MOSS, M.O. Structure and Formation of Mycotoxins. In: (Ed.). Mycotoxins: formation, analysis and significance. New York: John Wiley \& Sons, 1985. Chapter 3, p.31-49.

VICAM. Aflatest instruction manual.Vicam, Watertown, MA: Vicam, 2002.

WANGIKAR, P.B.; DWIVEDI, P.; SINHA, N.; SHARMA, A.K.; TELANG, A.G. Effects of aflatoxin $B_{1}$ on embryo fetal development in rabbits. Food and Chemical Toxicology, n.43, p.607-615, 2005.

YANAKA, E.K.; PONTES NETTO, D.; SASSAHARA, M.; TAJIRI, A.N.; OLIVEIRA, A.M. Avaliação da presença de micotoxinas em milho (Zea mays linné) e em rações destinadas à avicultura comercial de postura nas regiões norte e noroeste do estado do Paraná. PUBVET. Londrina: 2007. v.1, n.9. Disponível em: <http://www. pubvet.com.br/texto.php?id=92>. Acesso em: 22 jul. 2009.

YU, J.; MOHAWED, S.M.; BHATNAGAR, D.; CLEVELAND, T.E. Substrate-induced lipase gene expression and aflatoxin production in Aspergillus parasiticus and Aspergillus flavus. Journal of Applied Microbiology, v.95, p.1334-1342, 2003.

Recebido em 27/12/07

Aceito em 26/7/09 